\title{
EUROPEAN-LED CLIMATE POLICY VERSUS GLOBAL MITIGATION ACTION: IMPLICATIONS ON TRADE, TECHNOLOGY, AND ENERGY*
}

\author{
ENRICA DE CIAN ${ }^{\dagger}, \| l \mid$, ILKKA KEPPO ${ }^{\star}$, JOHANNES BOLLEN ${ }^{\S}$, \\ SAMUEL CARRARA ${ }^{\dagger}$, HANNAH FÖRSTER ${ }^{\|}$, MICHAEL HÜBLER ${ }^{* *}$, \\ AMIT KANUDIA $^{\dagger \dagger}$, SERGEY PALTSEV ${ }^{+*}$, RONALD D. SANDS $\$ \$$ and \\ KATJA SCHUMACHER \\ †Fondazione Eni Enrico Mattei (FEEM) \\ Euro-Mediterranean Center on Climate Change (CMCC) \\ Isola di San Giorgio Maggiore, 30124 Venezia, Italy \\ University College London, UCL Energy Institute, \\ 14 Upper Woburn Place, London, WC1H ONN, UK \\ ${ }^{\S}$ Centraal Planbureau t.a.v. Johannes Bollen \\ P. O. Box 80510, 2508 GM, The Hague \\ "Öko-Institut, Germany \\ Schicklerstraße 5-7, 10179 Berlin, Germany \\ ${ }^{* *}$ Centre for European Economic Research (ZEW), \\ P. O. Box 103443 \\ 68034 Mannheim, Germany \\ HKanORS-EMR, SDF L-7B, \\ NSEZ, Dadri Road Phase II, Noida UP 201305, India \\ Massachusetts Institute of Technology, \\ 77 Massachusetts Ave, E19-411 \\ Cambridge, MA 02139, USA \\ ${ }^{\S}$ U.S. Department of Agriculture, Economic Research Service, \\ 1400 Independence Ave. SW, Mail Stop 1800, Washington DC 20250, USA \\ I|| enrica.decian@feem.it
}

Published 25 November 2013

\begin{abstract}
This paper examines how changes in an international climate regime would affect the European decarbonization strategy and costs through the mechanisms of trade, technology, and innovation. We present the results from the Energy Modeling Forum (EMF) model comparison study on European climate policy to 2050. Moving from a no-policy scenario to an existing-policies case reduces all energy imports, on average. Introducing a more stringent climate policy target for the EU only leads to slightly greater global emission reductions. Consumers and producers in Europe bear
\end{abstract}

\footnotetext{
*The views expressed are those of the authors and should not be attributed to their employers.

IIIICorresponding author.

This is an Open Access article published by World Scientific Publishing Company. It is distributed under the terms of the Creative Commons Attribution 3.0 (CC-BY) License. Further distribution of this work is permitted, provided the original work is properly cited.
} 


\title{
E. De Cian et al.
}

\begin{abstract}
most of the additional burden and inevitably face some economic losses. More ambitious mitigation action outside Europe, especially when paired with a well-operating global carbon market, could reduce the burden for Europe significantly. Because of global learning, the costs of wind and especially solar-PV in Europe would decline below the levels observed in the existing-policy case and increased R\&D spending outside the EU would leverage EU R\&D investments as well.
\end{abstract}

Keywords: Climate change; stabilization policy; international participation.

\section{Introduction}

In 2011, the European Commission presented "A Roadmap for moving to a competitive low carbon economy in 2050" (EU Roadmap, European Commission, 2011). This Roadmap envisages a reduction of European Union (EU-27, in the following EU) greenhouse gas (GHG) emissions by at least $40 \%$ in 2030 and $80 \%$ in 2050, compared to 1990 levels. The EU views these emission reductions as consistent with limiting the global temperature increase to about $2^{\circ} \mathrm{C}$ above the preindustrial level. Such reductions are likely to require energy efficiency improvements across the sectors and a substantial restructuring of energy supply, particularly of electricity. For example, the EU Roadmap expects an expansion of the share of renewable energies in electricity generation to $50 \%$ or more by 2050 . However, remaining below the $2^{\circ} \mathrm{C}$ temperature target requires substantial emission reductions beyond the EU on a global scale, or at least by the main carbon emitters.

Europe is connected to the rest of the world through international trade in energy and nonenergy commodities, both in intermediate and final forms, in emission permits, and through international technology transfers. Therefore, a more stringent climate policy in Europe will have an impact on international markets and on the rest of the world. Conversely, global climate action, or inaction, will have an impact on European production and trade, on the structure of the European energy system, and on the costs of complying with the Roadmap. If the EU reduces the use of internationally traded fuels dramatically, it could affect international energy prices, potentially incentivizing higher demand in countries with less stringent regulations. The literature refers to this channel as the energy market effect (Burniaux and Oliveira-Martins, 2000). Energy-intensive (EI) industries could relocate to locations outside Europe where lower energy input costs provide more competitive conditions for production. This effect is known as pollution haven hypothesis or competitive channel. These effects can lead to carbon leakage, and prior literature looked at border measures as a solution (Böhringer et al., 2012; Boeters and Bollen, 2012). Boeters and Bollen (2012), using one specific model, show that most of the leakage by 2020 will occur through the energy market effect (almost 90\%) because of relatively high prices of fossil energy in the Business-As-Usual scenario. Climate policy, by increasing energy prices, can also stimulate innovation and diffusion in carbon — and energy-saving technologies (Carraro et al., 2010). This may be referred to as the Porter Hypothesis, which implies that more stringent environmental policies can lead to higher productivity and enhanced competitiveness if implemented correctly. With integrated and global markets, technologies can diffuse to other regions through climate 
policy mechanisms, such as the Clean Development Mechanism (CDM) of the Kyoto Protocol (Dechezleprêtre et al., 2008) or through trade flows, multinational enterprises, and skilled-labor mobility (Keller, 2010). If such a technology effect is sufficiently strong, it can even induce countries with a less stringent policy to reduce rather than increase emissions (Bosetti and De Cian, 2013). Using bottom-up models of the energy sector, Barreto and Kypreos (2002) and Barreto and Klaassen (2004) show that technology spillovers can induce technical change and emission reduction outside the group of countries facing an emission constraint.

If the rest of the world implements climate policies of comparable stringency, the EU decarbonization strategy and the implementation costs could change. In particular, the option of a global carbon market, where Europe could sell and buy abatement, would significantly affect EU's domestic emission levels, technology choices, and costs of the transition. A recent assessment of the EU Roadmap with the PACE model in fact shows that the international regime strongly influences the results in Europe. In particular, international emissions trading can significantly curtail the additional mitigation costs of the EU Roadmap 2050 (Hübler and Löschel, 2013).

This paper contributes to the literature on regionally asymmetric mitigation regimes (see e.g., Clarke et al., 2009; Keppo and Rao, 2007; Böhringer et al., 2012), with a more focused analysis on the implied alternative abatement structures for Europe when the European climate policy strategy interacts with changes in the international climate regime. A number of numerical modeling studies have examined the economic effects of EU climate policy and the CDM by 2012 (Bollen et al., 1999; Klepper and Peterson, 2006) or until 2020 (e.g., Böhringer et al., 2009; Bollen et al., 2011). The new EU Roadmap extends the policy modeling period to 2050. To our knowledge, only the European Commission (2011) applying the POLES and GEM E3 ${ }^{1}$ models, and Hübler and Löschel (2013) using the PACE model, have assessed the new EU Roadmap 2050. This study presents results from the Energy Modeling Forum (EMF-28) model comparison project on European climate policy to 2050. It contributes to the literature on the EU Roadmap with a comparative analysis across eight different models ${ }^{2}$ of realignments in energy and nonenergy trade patterns between Europe and the rest of the world, of changes in the primary energy mix, research and development (R\&D), and renewable investment strategies, as well as of the implications on consumption and gross domestic product (GDP). The strength of computable general equilibrium (CGE) models is the representation of production and trade of goods with high sectoral resolution. The strength of optimal growth models (OGM) is the representation of international technology spillovers and inter-temporal optimization of energy system investments, while the strength of energy system models (ESM) is the detailed representation of the energy system with various technology options. By combining output from alternate model types we are able to explore the implications different climate policy regimes have on energy markets, trade, and technology.

\footnotetext{
${ }^{1}$ European Commission, Directorate General (DG) Research, Brussels.

${ }^{2}$ The eight global models that participated to the EMF-28 project include general equilibrium models (EPPA, FARMEU, PACE), OGMs (MERGE-CPB, WITCH), and ESMs (POLES, TIAM-UCL, TIMES-VTT).
} 
The remainder of the paper is structured as follows. Section 2 describes scenario design and the models used in the analysis. Section 3 studies energy markets and prices. Section 4 analyzes changes in the European energy technology mix and innovation. Section 5 presents a macroeconomic assessment of the various scenarios. Section 6 concludes.

\section{Models and Scenarios}

Economies are interconnected through a number of channels, including trade of goods, services, exchange of technologies, knowledge and financial flows. As a consequence, climate policy and regulations implemented in a small group of countries would affect other economies as well. This paper explores the linkages between Europe and the rest of the world by analyzing the EMF-28 scenarios of fragmented and global action, focusing on the three major sources of international interaction, namely international trade, energy markets, and technology. In the suite of EMF-28 models, there is no

Table 1. Characterization of international mechanisms in the EMF-28 global models.

\begin{tabular}{|c|c|c|c|c|c|}
\hline Model & Model reference & $\begin{array}{l}\text { International } \\
\text { trade of goods }\end{array}$ & $\begin{array}{l}\text { Energy market } \\
\text { effect }\end{array}$ & $\begin{array}{c}\text { Technology } \\
\text { endogenous learning } \\
\text { and diffusion }\end{array}$ & Model type \\
\hline EPPA & $\begin{array}{l}\text { Paltsev et al. (2005) } \\
\text { and Paltsev } \\
\text { et al. }(2011)\end{array}$ & Yes & Yes & No & CGE \\
\hline PACE & $\begin{array}{l}\text { Böhringer and } \\
\text { Lange (2003), } \\
\text { Hübler and } \\
\text { Löschel (2013), } \\
\text { Böhringer et al. } \\
\text { (2009) and } \\
\text { Böhringer and } \\
\text { Löschel (2006) }\end{array}$ & Yes & Yes & No & CGE \\
\hline FARM-EU & $\begin{array}{l}\text { Sands et al. } \\
\quad \text { (forthcoming) }\end{array}$ & Yes & Yes & No & CGE \\
\hline WITCH & Bosetti et al. (2006) & No & Yes & Yes & OGM \\
\hline MERGE-CPB & $\begin{array}{l}\text { Blanford et al. } \\
\qquad(2009) \text { and } \\
\text { Bollen (2013) }\end{array}$ & No & Yes & Yes & OGM \\
\hline POLES & $\begin{array}{l}\text { Criqui and Mima } \\
\text { (2012) }\end{array}$ & No & Yes & Yes & ESM \\
\hline TIAM-UCL & $\begin{array}{l}\text { Anandarajah et al. } \\
\text { (2011) }\end{array}$ & No & Yes & No & ESM \\
\hline TIMES-VTT & $\begin{array}{l}\text { Koljonen and } \\
\text { Lehtilä (2012) }\end{array}$ & No & Yes & No & ESM \\
\hline
\end{tabular}

${ }^{*} \mathrm{CGE}=$ Computable General Equilibrium Model, ESM = Energy System Model, OGM = Optimal Growth Model. More detailed information regarding each model is available in Knopf et al. (2013). 
single model that describes all the three channels, but by analyzing the output of eight different models, we are able to provide a discussion of the three mechanisms in detail.

Table 1 lists the models considered in the analysis and indicates to what extent each model accounts for the three mechanisms of international interaction just mentioned. All models can simulate the energy market effect, though details may differ. CGE models characterize international trade of energy and commodities, energy markets, but they do not represent technology diffusion or learning. OGMs characterize the energy market effects as well as technology learning and knowledge spillovers, but they neglect international trade. ESMs only characterize the energy market effect, though with greater detail than other models. International trade in goods and the energy market effects are arguments that make unilateral action unattractive. Because of them, the implementing countries can lose competitiveness and the increased use of fossil fuels by unconstrained regions can undermine the environmental effectiveness of unilateral climate action. In contrast, the technology effect, and more precisely the possibility that EU becomes a leader in clean technologies and sells them to the rest of the world is an argument that could make the unilateral action more attractive (Bosetti and De Cian, 2013). Only three models out of eight account for technology innovation and diffusion, mostly through global learning in decarbonization technologies. No model explicitly captures the potential domestic industry effects that being a global technology leader might bring about, however. Section 4 looks into this effect by comparing results from the WITCH and MERGE-CPB models.

Among the scenarios considered in the EMF-28 exercise, we consider the subset of cases that varies the ambitiousness of climate policy in Europe and in the rest of the world, under two alternative technology pathways, a default case and one with more optimistic assumptions for the improvement of energy efficiency (see Table 2). The no policy scenario (BASE) is used as a counterfactual for diagnostic purposes. It allows evaluating the context and policy costs of the reference policy (with default $40 \% \mathrm{DEF}$, and enhanced energy efficiency $40 \%$ DEF_EFF), which reflects implementation and continuation of existing policies in the EU, including the climate and energy package. The context of this scenario differs from model to model, as no baseline harmonization has been done and models can therefore have different assumptions concerning the development of drivers such as GDP, population, and technology. The reference policy includes the $20 \%$ emission reduction target for 2020 and the binding target of $20 \%$ renewable energy in final energy consumption by 2020 , but excludes the $20 \%$ reduction in primary energy use, as this is not currently a binding target. The reference policy has a moderate long-term target of $40 \%$ GHG reductions by 2050 and it is meant to describe a fragmented world where moderate climate policy is implemented but with regional or national schemes. As a consequence, the Rest of World (ROW) is assumed to follow a moderate, muddling through policy scenario. The scenario used here has been designed within the RoSE project ${ }^{3}$ (Luderer et al., 2013) and it reflects

${ }^{3}$ http://www.rose-project.org/. 
Table 2. Definitions of the EMF-28 scenarios assessed.

\begin{tabular}{|c|c|c|c|c|}
\hline $\begin{array}{l}\text { Climate policy } \\
\text { dimension }\end{array}$ & $\begin{array}{l}\text { Policy dimension for the } \\
\text { EU }\end{array}$ & $\begin{array}{l}\text { Policy dimension for the } \\
\text { Rest of the World (ROW) }\end{array}$ & Default & $\begin{array}{l}\text { Higher energy } \\
\text { efficiency }\end{array}$ \\
\hline $\begin{array}{l}\text { No Policy } \\
\text { Baseline }\end{array}$ & No policy & No policy & BASE & \\
\hline Reference & $\begin{array}{l}\text { Including the } 2020 \text { tar- } \\
\text { gets and } 40 \% \text { GHG } \\
\text { reduction by } 2050\end{array}$ & $\begin{array}{l}\text { Moderate policy scenario; } \\
\text { no emission trading } \\
\text { across macroregions (but } \\
\text { trade within macro- } \\
\text { regions e.g., within EU) }\end{array}$ & $40 \% \mathrm{DEF}$ & $40 \% \mathrm{EFF}$ \\
\hline Mitigation 1 & $\begin{array}{l}80 \% \text { GHG reduction by } \\
2050 \text { (with Cap and } \\
\text { Trade within the EU, } \\
\text { a carbon market in } \\
\text { the EU only) }\end{array}$ & $\begin{array}{l}\text { Moderate policy scenario; } \\
\text { no emission trading } \\
\text { across macroregions (but } \\
\text { trade within macro- } \\
\text { regions e.g., within EU) }\end{array}$ & $80 \%$ DEF & $80 \% \mathrm{EFF}$ \\
\hline Mitigation 2 & $\begin{array}{l}80 \% \text { GHG reduction by } \\
2050 \text { (with Cap and } \\
\text { Trade within the EU, } \\
2 \text { separate carbon } \\
\text { markets) }\end{array}$ & $\begin{array}{l}\text { IMAGE } 2.9 \text { scenario; full } \\
\text { emission trading for } \\
\text { ROW, but no emission } \\
\text { trading between ROW } \\
\text { and EU. Regional rela- } \\
\text { tive contributions to } \\
\text { mitigation based on the } \\
\text { Mitigation } 1 \text { scenario }\end{array}$ & $80 \%$ FRAG & $80 \%$ FRAG_EFF \\
\hline Mitigation 3 & $\begin{array}{l}80 \% \text { GHG reduction by } \\
2050 \text { (with full Cap } \\
\text { and Trade, } 1 \text { global } \\
\text { carbon market) }\end{array}$ & $\begin{array}{l}\text { IMAGE } 2.9 \text { scenario; emis- } \\
\text { sion trading is allowed } \\
\text { between all regions }\end{array}$ & $80 \%$ GLOB & $80 \%$ GLOB_EFF \\
\hline
\end{tabular}

existing climate policies, a weak interpretation of the 2020 Copenhagen Pledges, and an extrapolation of these targets beyond 2020 based on emissions intensity (GHG emissions per unit of GDP). There is no international cooperation and international carbon trading is excluded.

The Mitigation 1 (with default technology $80 \%$ DEF, and enhanced energy efficiency $80 \%$ DEF_EFF) policy evaluates the implications of an attempted EU lead in climate action. The EU commits to a GHG emission reduction target of $80 \%$, even though climate policy in the rest of the world remains much less ambitious. Other countries do take some action, similar to that in the reference scenario, but they clearly fall short of what the EU is doing. This creates a strong asymmetry between the efforts of the EU and rest of the world. By 2050 the EU is discouraged by the inaction of others and adjusts its ambition accordingly, with a gradual transition into global muddling through after 2050. ${ }^{4}$ Mitigation 1 is therefore a pessimistic scenario in which EU takes early action, hoping to convince others to follow, but is unsuccessful at doing this.

\footnotetext{
${ }^{4}$ Some models run up to 2100 and the assumptions post-2050 can affect the results pre-2050 because of banking and perfect foresight.
} 
The more optimistic outcome in which the EU succeeds at getting other countries to join a more serious climate regime is described by the scenarios Mitigation 2 and 3. In the Mitigation 2 (with default technology $80 \%$ FRAG, and enhanced energy efficiency 80\% FRAG_EFF) cases, the EU climate leadership spills over to other countries, which also take on more ambitious action compared to Mitigation 1 and reference. The emission path for the ROW has been derived from the global IMAGE scenario (Van Vuuren et al., 2007) that stabilizes 2100 radiative forcing at $2.9 \mathrm{~W} / \mathrm{m}^{2}$. In Mitigation 2, EU and ROW have separate carbon markets and the EU does not trade with the ROW. Carbon trade between the EU and ROW is allowed in the Mitigation 3 (with default technology 80\% GLOB, and enhanced energy efficiency $80 \%$ GLOB_EFF) scenarios, which consider the case of a global carbon market. Scenarios for Mitigation 2 and 3 policies allow us to separate the effect of global action from that of global emission trade and assessing the impact of both of these effects on the European mitigation strategy.

An important assumption in the EMF-28 scenarios regards the international trade of bioenergy as all scenarios assume that international trade of bioenergy is limited. ${ }^{5}$ Although the EU Energy Roadmap acknowledges the importance of biomass as a mitigation option, land-based bioenergy options need be compatible with other biodiversity objectives and with the sustainability of agriculture and food security. A situation in which the world does not take global action and the EU action results in an increase in bioenergy needs, with negative indirect implications in other parts of the world due to EU imports, is considered as undesirable. ${ }^{6}$ It is important to mention that, although default and higher energy efficiency scenarios are considered, the analyses do not fully explore the implications of different technology assumptions and of different views about future technological change as assumed in the models. Variation in technology assumptions is embedded in the different model structures and energy technology options are not equal across models. In particular, some models (PACE) do not include the option of carbon dioxide capture and storage (CCS) whereas others (EPPA) include it, but at a cost that is so high that the adoption of the technology is not feasible from an economic point of view. ${ }^{7}$

Figure 1 summarizes the European and global emission pathways, as produced by the models. ${ }^{8}$ In the no policy baseline the range of global $\mathrm{CO}_{2}$ emissions in 2050 is significant, about $34 \mathrm{Gt} \mathrm{CO}_{2}$. European $\mathrm{CO}_{2}$ emissions in 2050 vary from 3.6 to $7.2 \mathrm{Gt}$ $\mathrm{CO}_{2}$. While in some models EU emissions without climate policy will remain constant over the next four decades, other models foresee an increase of 50\%. Whereas this gap narrows in Europe in the reference and mitigation scenarios, at the global level it remains

\footnotetext{
${ }^{5}$ There is not a quantitative limit that was adopted by all models. Modelers were asked to assume relatively limited international trade in bioenergy. EU bioenergy should largely be grown domestically, with the exception of existing trade, for example, in ethanol. Modelers should choose the most appropriate means to treat bioenergy trade, but with the goal of avoiding major distortions that would result from large-scale bioenergy imports.

${ }^{6}$ See Economic Assessment of the EU Roadmap, page 116.

${ }^{7}$ The EPPA model includes a small additional cost penalty for CCS in Europe which reflects public nonacceptance of this technology. Even without the penalty, CCS would not be operational in the scenarios considered in this paper.

${ }^{8}$ Note that some models only include fossil fuel emissions and do not include process emissions.
} 

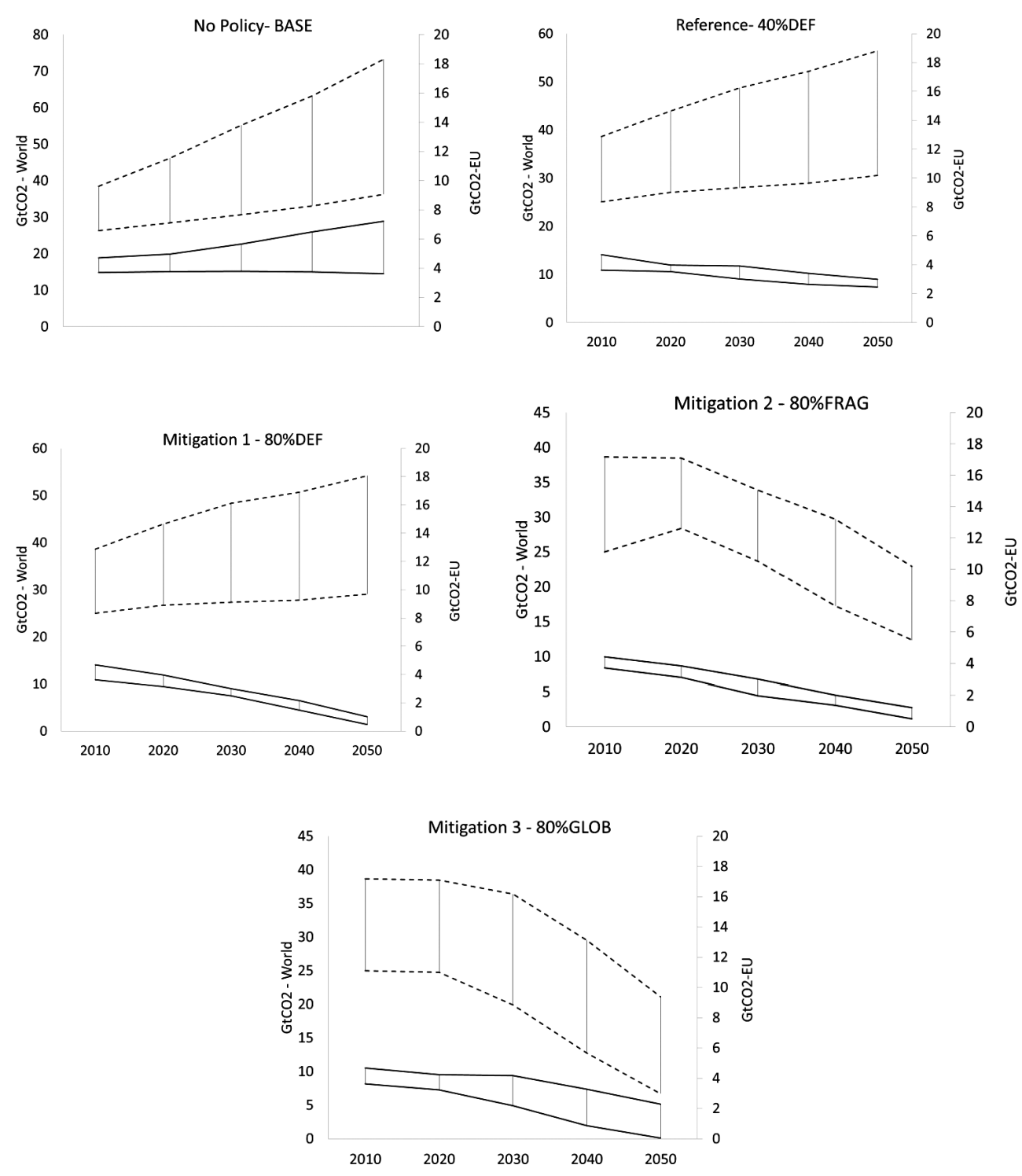

Figure 1. $\mathrm{CO}_{2}$ emissions in the no policy baseline, reference, and mitigation scenarios for EU27 (solid lines, right axis) and the world (dashed lines, left axis) in the default technology case. Ranges are computed using results from the models EPPA, FARM-EU, MERGE-CPB (not included in Mitigation 3), PACE, POLES, TIAM-UCL, TIMES-VTT (not included in Mitigation 2), WITCH and TIAM-UCL (not included in Mitigation 1 and 2).

significant. As can be expected, global emissions show more convergence in the Mitigation 2 (80\% FRAG) and 3 (80\% GLOB) scenarios, which have been designed to be consistent with the objective of limiting global warming to $2^{\circ} \mathrm{C}$. In both scenarios, global emissions peak in 2020 and on average decline about $50 \%$ by 2050 (relative to 2010). The Mitigation 1 and Mitigation 2 scenarios are very close to the global scenarios examined in the Energy Roadmap for Europe (European Commission, 2011). 


\section{Energy Markets}

This section analyzes the implications of policy action on energy prices and energy trade, which, as summarized in Table 1, is the most widely represented effect across models.

\subsection{Reference policies versus no policy case}

Figure 2 describes model-specific trade results for the no policy (BASE) and reference (40\% DEF) scenarios. When climate policies are introduced (BASE versus 40\% DEF), oil and coal imports are reduced in all models, while results are less clear for gas. These differences across models reflect the impact of baseline assumptions on import patterns and the somewhat ambigious role gas plays in a mitigation context. For example, coal use is high in TIAM-UCL in the BASE scenario and increased gas imports largely replace coal imports in the $40 \%$ DEF scenario. PACE, in turn, has much lower coal use in the BASE case and, as total primary energy demand also declines more than in TIAM-UCL, a significant decrease in gas imports is observed.

Prices, in turn, are not very strongly affected by the mitigation required in $40 \%$ DEF and this is especially true for fuels for which there is a global price (coal and oil). Since gas trade relies more on expensive, often bilateral trade infrastructures (gas pipelines), the impact of reduced EU demand is more visible in the price of gas, especially for PACE. The price differences across the models are small for coal, but significant differences exist for gas and especially oil. This is at least partially explained by price formation in different models. In TIAM-UCL and TIMES-VTT, for example, price reflects the marginal extraction costs, exhaustability, and replaceability of the resource. Since these models operate under perfect foresight and implicitly assume a social planner, prices are likely to be clearly below those experienced in the real
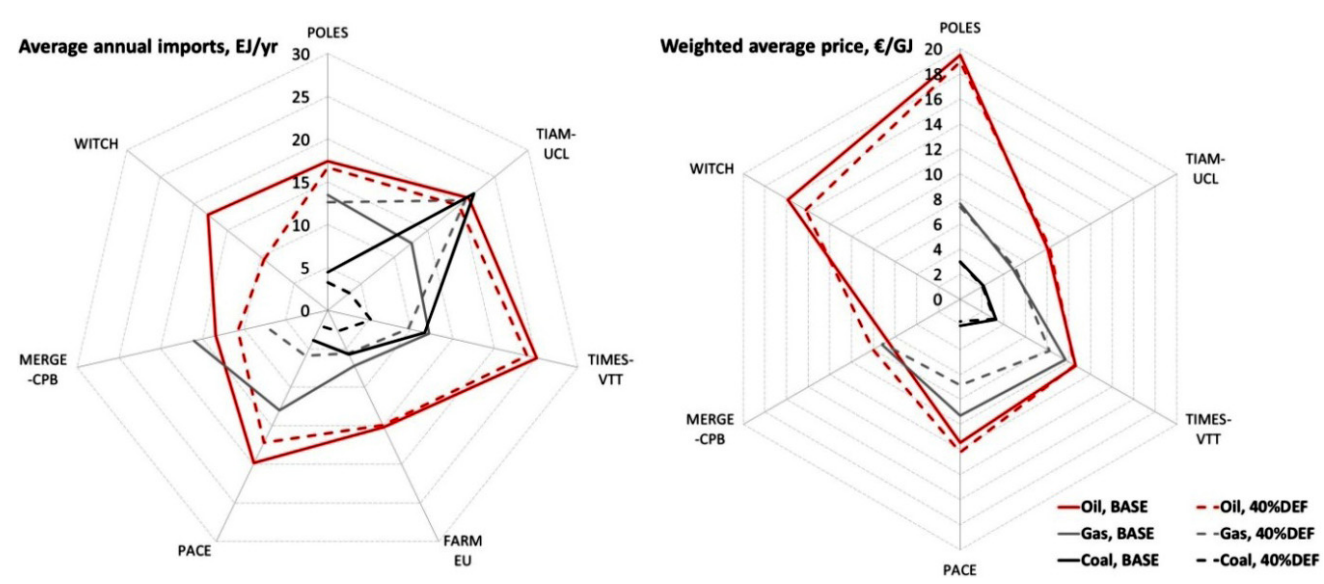

Figure 2. Average 2020-2050 annual net fossil fuel imports (left panel) and import-volumeweighted fuel price per model for the no policy (BASE) and reference (40\% DEF) scenarios (FARM-EU did not report prices and is therefore not included in the right panel). 


\section{E. De Cian et al.}

world (i.e., the impact of market power, uncertainty, production and infrastructure bottlenecks, etc. are not accounted for). The WITCH model calibrates its prices to energy statistics for the base year and adds a mark up on top of the marginal extraction cost for future years.

The volumes and prices shown in Fig. 2 can be used to calculate the implied import expenditures. Considering only the models that give prices and include all three fuels (PACE, POLES, TIAM-UCL, and TIMES-VTT), average annual import expenditure across the four models and for the period 2020-2050 declines by about 15\%, some 54 billion€/yr, when moving from BASE to $40 \%$ DEF. The range for import cost reductions is wide, from $\sim 4.5$ billion€/yr (TIAM-UCL) to over 100 billion€/yr (PACE), as the ranges for prices and volumes shown in Fig. 2 already suggested.

\subsection{Mitigation policies versus reference policies}

Figure 3 shows how fossil fuel import volume changes in the various mitigation scenarios. The effect of more efficient end-use technologies (high energy efficiency case) is also shown with darker bars. Nearly all models reduce imports of all fuels when moving from reference to Mitigation 1 or Mitigation 2, gas imports in MERGE$\mathrm{CPB}$ being the lone exception. However, it is more difficult to draw unequivocal conclusions on the impacts of moving from Mitigation 1 to Mitigation 2, as a relatively small number of models have evaluated the Mitigation 2 scenarios. The general

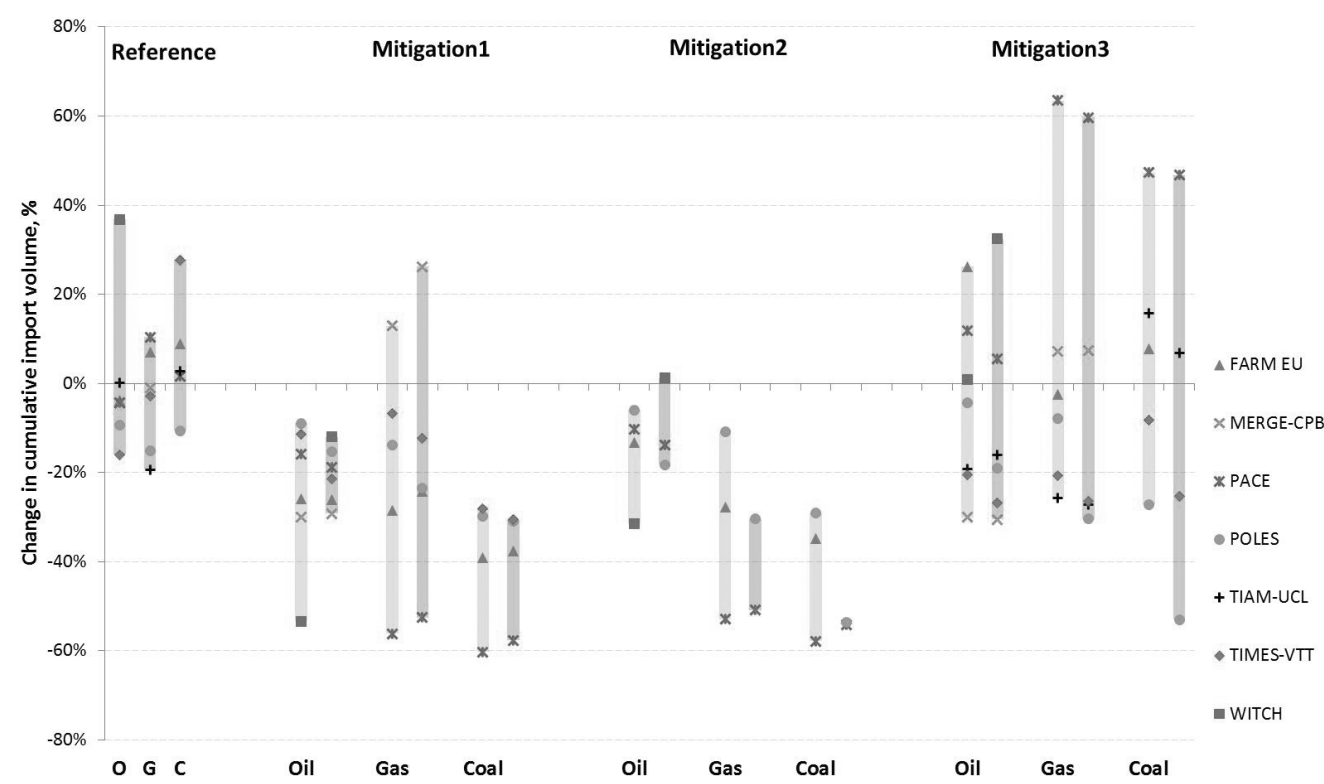

Figure 3. Impact of climate policy scenario and energy efficiency on cumulative (2020-2050) fossil fuel import volume. Differences are calculated against the reference scenario (40\% DEF). Lighter bars reflect default technology scenarios, darker bars high energy efficiency scenarios. Markers show individual model results. 
consensus among these few models is that the introduction of a global mitigation regime may slightly increase energy imports of the EU in volume, but the impact on expenditures is mitigated by the depressed fossil fuel prices, caused by reduced global demand.

If emission trading is allowed (Mitigation 3), model-specific results change significantly. The range across the models is wide and models do not agree on whether fuel imports would increase or decrease compared to reference. Compared to Mitigation 1, the general trend for Mitigation 3 shows imports increasing, although some models do suggest fairly constant, or even decreasing import volumes. In some cases these differences are related to EU's role within the global emission trading market. While most models suggest EU to be a net buyer of permits, some models project EU to be a net seller or to have very little permit trade with the rest of the world. Assumptions concerning regional mitigation potentials are likely to play a key role in determining EU's role in the market.

The impact of technology is ambigious, as some models suggest increasing, and others decreasing, import volumes with improved end-use efficiency options available. For some models the trend is also fuel- and scenario-specific. On a more general level, the assumptions concerning end-use technologies do not have a significant impact on energy trade for most models, at least not compared to the impact of the mitigation regime. The clearest exceptions of this rule are WITCH and POLES, which can be equally sensitive to end use efficiency assumptions as they are to mitigation levels. This appears to be caused by the price impact of the efficiency assumptions, which is for these models clearly stronger than it is for other models. These two models do not agree on the impact of the improved efficiency, though, as POLES reduces imports with high end use efficiency while WITCH increases them. This may be related to how these two models have implemented the efficiency scenarios and to the partial endogeneity of energy efficiency in the WITCH model, where R\&D investments increase energy productivity.

To gain further insights about how and why import expenditures are affected by the mitigation activities, we first calculate the changes in import expenditures compared to $40 \%$ DEF and split the factors behind the expenditure changes for all models and all mitigation scenarios into three components: price, volume, and structure ${ }^{9}$ (see Fig. 4). ${ }^{10}$ The volume element covers the changes in the total volume of imports, the price component considers the contribution of the fuel-specific price changes, and the structural factor accounts for the impacts of changes in the composition of the import portfolio (i.e., what are the shares of different imported fuels in the total import volume).

Cumulative import expenditure is reduced for all models when the mitigation target is changed from reference policy to that of Mitigation 1 (bottom bars of both panels of Fig. 4). With default technology, almost the entire reduction is explained by a lower volume, as prices change fairly little. Most models also suggest that the relative shares

\footnotetext{
${ }^{9}$ Structure reflects share changes for fuel volumes in the import portfolio.

${ }^{10}$ Logarithmic Mean Divisia Index (LMDI, see Ang, 2005) has been used for the decomposition.
} 


\section{Default technology}

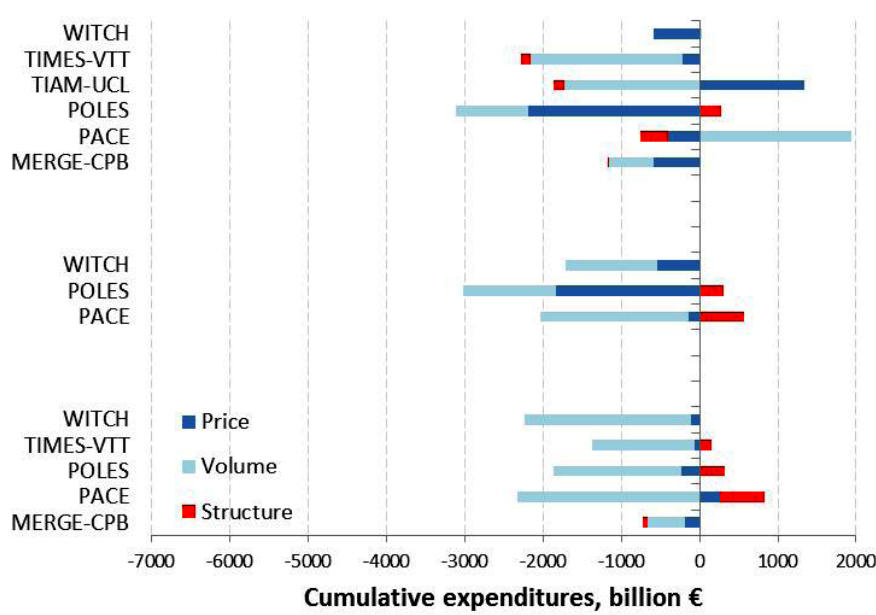

Mitigation 3

Mitigation 2

Mitigation 1

High energy efficiency

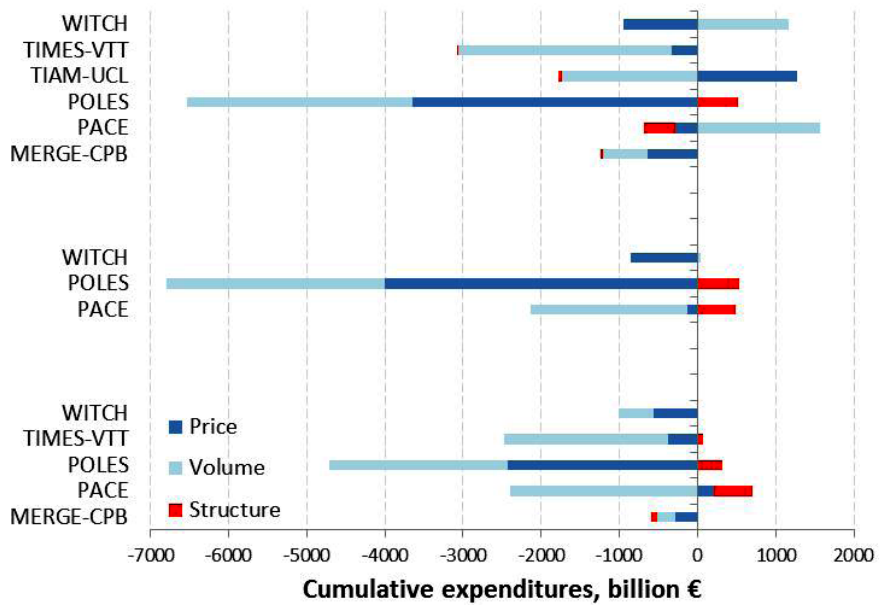

Mitigation 3

Mitigation 2

Mitigation 1

Figure 4. Decomposition of the changes in cumulative (2020-2050) fossil fuel import expenditures compared to the reference case (40\% DEF) in price, volume, and structure effects. Top figure with default technology (80\% DEF, 80\% FRAG and 80\% GLOB, from bottom to top), bottom with high energy efficiency (80\% DEF_EFF, 80\% FRAG_EFF and 80\% GLOB_EFF). Structure reflects changes in the fuel volume shares in the import portfolio (WITCH reports trade only for oil, and MERGE-CPB only for oil and gas. FARM-EU does not report prices and is therefore excluded).

of the three fuels in the import portfolio change, with cheap fuels such as coal having a lower share than in $40 \%$ DEF. Optimistic assumptions concerning the end use technologies, shown on the lower panel of Fig. 4, can either increase (WITCH), decrease (TIMES-VTT, POLES) or keep the import expenditures relatively unchanged (PACE, MERGE-CPB). The reasons for the import expenditure changes caused by alternative 
end use efficiency assumptions also differ across the models. WITCH, for example, suggests that the import expenditures increase because of much higher import volumes, while a price reduction mitigates this increase to an extent. POLES, on the other hand, suggests that expenditures drop drastically, mostly because of a significant reduction in prices, but also because of reduced import volumes. These differences reflect the different strategies chosen by the models, but also the specific ways in which the teams have implemented the high energy efficiency scenario.

The three models that report Mitigation 2 scenarios differ regarding their aggregated impacts in comparison to Mitigation 1 (middle rows of Fig. 4). POLES suggests that import expenditures are reduced due to significant price decrease, even if the import volume is increased. WITCH projects a more moderate price decline and an increase in expenditures, as the import volume increases. PACE has very similar expenditures across the two scenarios, with the moderate price impact being counterbalanced by a volume increase. Technology (lower panel of Fig. 4) emphasizes these dynamics, for WITCH and POLES in particular. The models therefore agree on how volume and price are affected qualitatively, but they disagree on the aggregated effect of these individual components, with the price reduction dominating in some models and volume increase in others.

Except for POLES, Mitigation 3 scenarios do not resemble the other mitigation scenarios for the other two mitigation levels, nor are they similar to the reference scenario $40 \%$ DEF. Neither are the models in agreement about the qualitative nature of the results. Compared to $40 \% \mathrm{DEF}$, each of the three factors (volume, price, structure) can contribute to either an increase or to a decrease in import expenditures, depending on the model one looks at. This diversity is likely to be an outcome of a range of differences across the models regarding, (1) the role of EU in the emission trading market, (2) model specific price mechanism and its sensitivity, and (3) the role of gas in the reference scenario. The first of the three explains why TIMES-VTT is the only model suggesting the import volume to go clearly down between Mitigation 1 and Mitigation 3, leading, in turn, to a reduction in import expenditures. Total import expenditures changes for POLES, MERGE-CPB, PACE, and WITCH relate mainly to the second item, to the interplay between the sensitivity of the fuel price and changes in import volumes. The price increase between reference and Mitigation 3 shown for TIAM-UCL relates to the item 3, the role of gas. Certain regions, such as China, significantly increase their gas use in the Mitigation 3 scenario, thus driving up the price of the supply.

Expenditure results across the models and scenarios are summarized in Fig. 5. Interestingly, high energy efficiency assumptions reduce the differences in import costs across the models, as it can be seen from the upper panel. POLES generally, but not always, provides the upper end of the range, whereas PACE and TIAM-UCL give the lower limit. These trends are mostly explained by the differences in prices (see Fig. 2 for an example). Interestingly, however, there is no single model combination for which we could say that one model always has higher import expenditures than the 


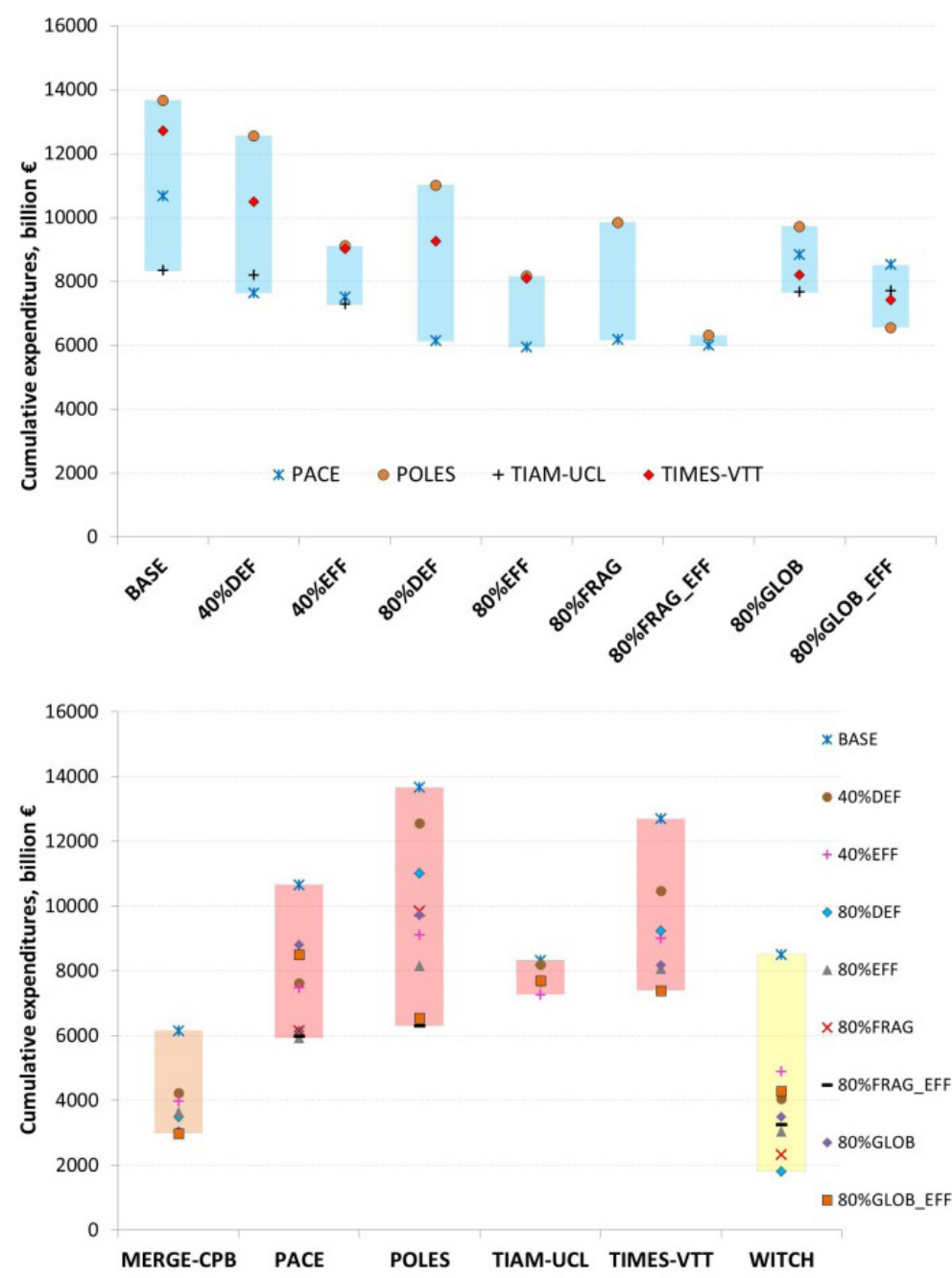

Figure 5. Ranges for cumulative (2020-2050) fossil fuel import expenditures across the models for each scenario (top panel) and summary of model specific import costs across scenarios (bottom panel). WITCH and MERGE-CPB report less fuels than the other models and are therefore excluded from the top panel and shown as the leftmost bar (two out of three fuels) and the rightmost bar (one out of three fuels) bars in the bottom figure.

other. The bottom panel of Fig. 5, in turn, shows how the import expenditures are much more sensitive to changes in assumptions in some models than in others. Some of the reasons behind these differences can be seen in Fig. 4, such as the significant price changes in POLES. Other models, like MERGE-CPB and especially TIAMUCL, suggest fairly minor variations across the scenarios. Price is relatively insensitive to scenario changes in TIAM-UCL and since this model did not find a feasible solutions for Mitigation 1 and Mitigation 2 scenarios, the narrow range is emphasized 
even more. MERGE-CPB does not consider coal imports, which contributes to the smaller variation in import expenditures.

Having characterized the adjustments in the international energy markets and prices, the next section analyzes the implications for the enery system and technology mix.

\section{Energy Systems and Technology}

The change in the policy landscape and the consequent adjustment in energy prices would alter investment decisions in the energy sector. Figure 6 shows the EU27 primary energy shares of low carbon technologies ${ }^{11}$ in 2030 and 2050 under different climate policies for the default technology assumptions.

The year 2030 marks a shift in the deployment of the fossil plants with CCS. The penetration of the technology is negligible in the reference scenario (40\% DEF), while it becomes substantial as the $80 \%$-mitigation target is imposed for the EU in Mitigation 1 (80\% DEF) and above all in Mitigation 2 (80\% FRAG), where the rest of the world follows with a more binding target. CCS is often considered a transition technology, and in fact it plays this role in about half of the models considered, exhibiting the largest variation across scenarios in the short-term. A number of models however achieve even the most stringent emission target by means of other technological options, namely energy efficiency and renewable (PACE, which does not include the CCS technology), or bioenergy (EPPA, where the CCS technology can be potentially used, but it is not convenient compared to the other options). Under the additional assumption of a global carbon market in the $80 \%$ GLOB scenario emission price in the EU declines and technology penetration of CCS slightly decreases because $\mathrm{CO}_{2}$ permits provide a cheaper substitute to that technology. Compared to 2020, no major differences are observed for the other three technologies in 2030. Biomass, nonbiomass renewables, and nuclear only slightly increase, in terms of median values. Nonbiomass renewables and nuclear show a little bit more evident variability across models. As pointed out for the year 2020, the effects of the different policies are quite irrelevant.

In 2050, a greater variability across models and across scenarios is observed. As discussed in Knopf et al. (2013), decarbonization becomes more important after 2030, while in the short-run energy efficiency is the leading emission reduction strategy in most models. This is also why models follow similar technology paths until 2030 and a greater variety in terms of primary energy shares is observed in 2050. A clear trend can be observed for nonbiomass renewables and nuclear. Models seem to agree in assigning them a higher share in the Mitigation 1 and Mitigation 2 scenarios, and lower weight in the reference and global trading Mitigation 3 scenario. Yet, the share of these technologies is always greater in the Mitigation 3 than the reference case. Note that the share of nonbiomass renewables and nuclear tends to be higher in models that do not foresee the option of combining fossil fuels with CCS at the carbon prices resulting

${ }^{11}$ Biomass, fossil-CCS, nonbiomass renewables, and nuclear. 
2030
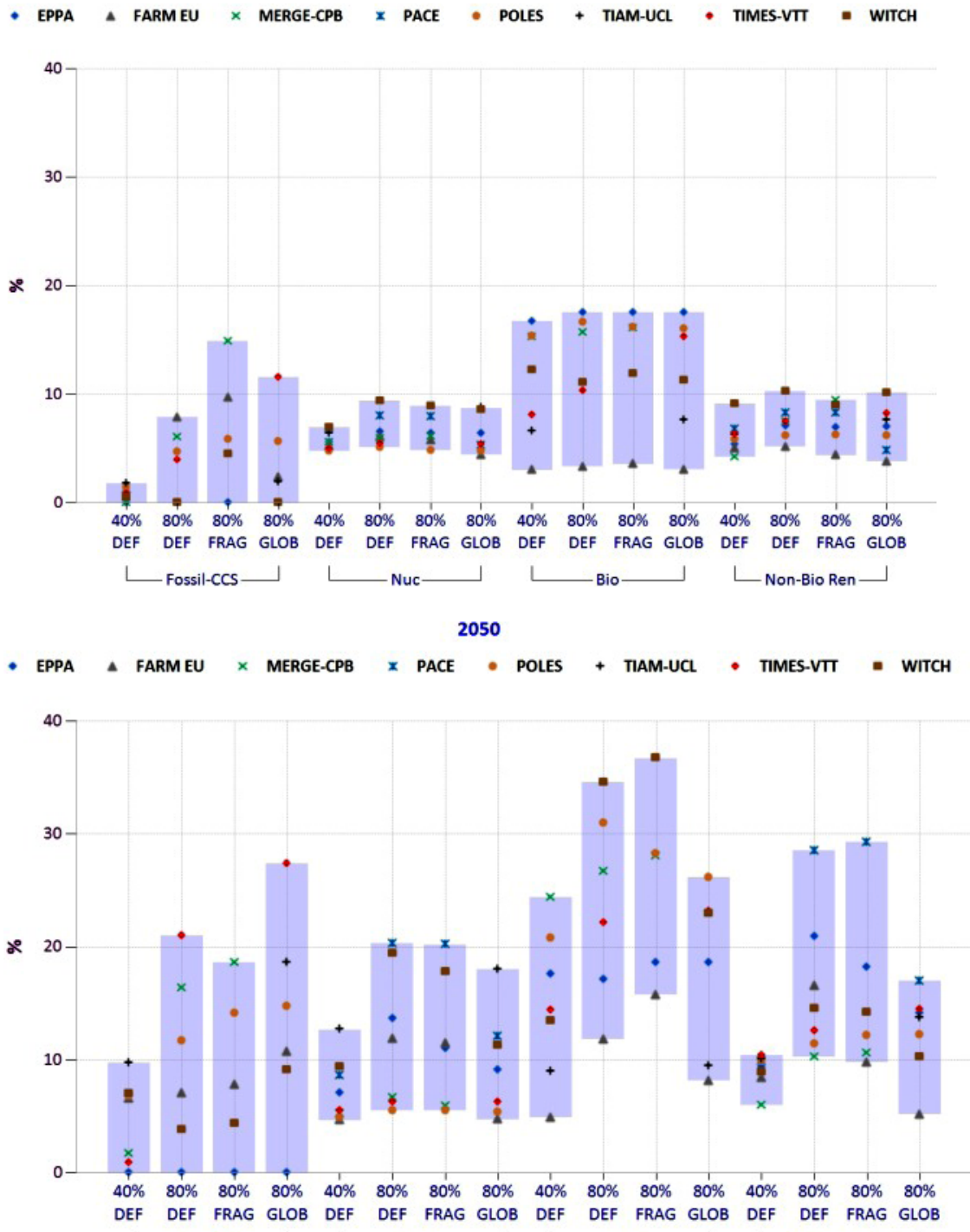

L Fossil-cCS —

L Non-Bio Ren -

Figure 6. Percentage share of various low carbon energy in total primary energy in 2030 and 2050 for the following models, EPPA, FARM-EU, MERGE-CPB, PACE, POLES, TIAMUCL, TIMES-VTT, WITCH. TIAM-UCL is not included in the scenarios Mitigation $1(80 \%$ DEF) and Mitigation 2 (80\% FRAG).

from these scenarios (PACE and EPPA). In general, renewables and nuclear heavily grow in terms of share. CCS too can become a technology of paramount importance, featuring the second highest share after biomass for many models.

A very similar behavior is found in the case with higher energy efficiency. For nonfossil technologies (biomass, nonbiomass renewables, and nuclear) results replicate 
those obtained in the corresponding default cases, both as a qualitative trend and as quantitative values. The only item that shows some variability, though small, is fossilCCS. In particular, in 2030 a reduction of its share is observed in the Mitigation 2 case, realigning the percentages with the Mitigation 3 one. In 2050, mitigation cases are substantially identical, but there is a considerable drop in the CCS share for the reference case, where the better performance in terms of high efficiency makes the deployment of such a technology unnecessary.

The change in the policy landscape and the consequent adjustment in energy prices also induces different investment behavior in $R \& D$ and new, cleaner technologies. Innovation and technology diffusion can make unilateral action more attractive if the EU succeeded at fostering clean technology adoption in other countries as well, but only two models out of eight characterize these effects in an endogenous way. The MERGE-CPB and WITCH models describe technology deployment and endogenous learning, while only the WITCH model represents innovation and R\&D investments in clean energy technologies.

Figure 7 plots the levelized cost $(2010 € / \mathrm{MWh})$ for wind and solar-PV in Europe against the generation $(\mathrm{PWh} / \mathrm{yr})$. Due to endogenous global learning, the cost of technologies in all regions, including Europe, correlates with the global cumulative production. The two models considered though have different perspectives on the learning potential of specific technologies. In the WITCH model solar-PV is absent, and most of the learning occurs in wind energy. On the other hand, in MERGE-CPB most of the learning occurs in solar-PV. Wind energy is characterized as a mature technology and therefore there is lower potential for reductions in levelized costs (LCOE). Despite these differences, both models show that when non-European regions implement stringent policies (Mitigation 3), more power will be generated from young energy technologies (wind in WITCH and solar-PV in MERGE-CPB) in the rest of the world, bringing down technology costs in Europe as well. ${ }^{12}$ Global action (Mitigation 3 versus Mitigation 2) only marginally affects the costs of wind in the EU, while a greater effect is seen on solar-PV. The costs of solar-PV would fall from 180 to 130 $2010 € / M W h$ by 2020 when also ROW adopt stringent emission reduction targets. On the other hand, the implementation of a more stringent climate policy target only in Europe (Mitigation 1 versus reference) does not significantly reduce the LCOE of neither wind nor solar-PV, suggesting that Europe alone would not be able to lower the costs of wind and solar-PV globally. This also implies that if additional export opportunities would arise from the unilateral EU action (compared to reference), these would be related to European companies capturing market share from non-EU companies, as opposed the volume of the global market growing due to EU action.

\footnotetext{
${ }^{12}$ WITCH and MERGE-CPB model learning in a different way. In WITCH, investment costs decline with capacity installed whereas in MERGE-CPB LCOE are directly linked to electricity produced. In WITCH, the wind investments cost reduction from Mitigation 1 to Mitigation 3 is greater than the reduction in LCOE.
} 

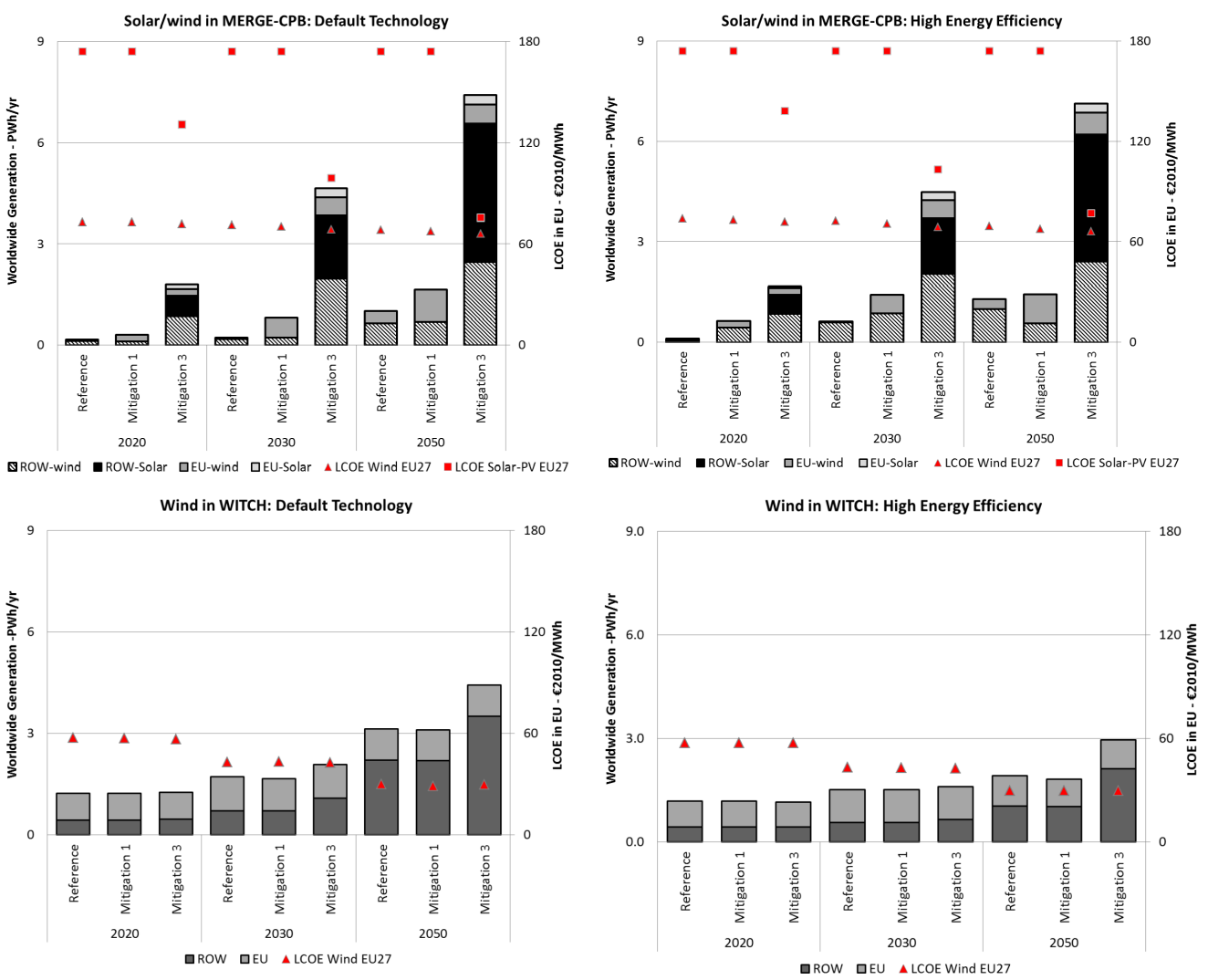

Figure 7. Worldwide generation (PWh/yr) and levelized costs (LCOE, $2010 € / \mathrm{MWh}$ ) in Europe for wind and solar-PV power. Results from the MERGE-CPB (upper panel) and WITCH (lower panel) models for the default (left panel) and high energy efficiency (right panel) cases.

The two lower panels of Fig. 7 show that learning is somewhat mitigated in the higher energy efficiency case for the WITCH model because of faster improvements in terms of energy efficiency. This also plays a role in the MERGE-CPB model, though to a lower extent. Although the high energy efficiency case requires less energy for all time, in the medium term, till 2030, there is more need to expand in solar-PV/wind to be able to still attain the benefits of lower costs in the longer run. These results indicate that the more ambitious action by the EU would not always succeed at fostering a significantly larger adoption of solar-PV and wind globally. Also, Bosetti and De Cian (2013) found that the technology diffusion effect induced by unilateral climate policy does not necessarily occur when the policy target is too stringent and the energy market effect (lock-in in fossil-fuel-based technologies because of low prices) prevails.

Figure 8 shows average annual clean energy R\&D investments in the WITCH model, distinguishing between R\&D in breakthrough technologies and in energy efficiency. The former represents a set of investments in a generic backstop or 
R\&D in WITCH: Default Technology

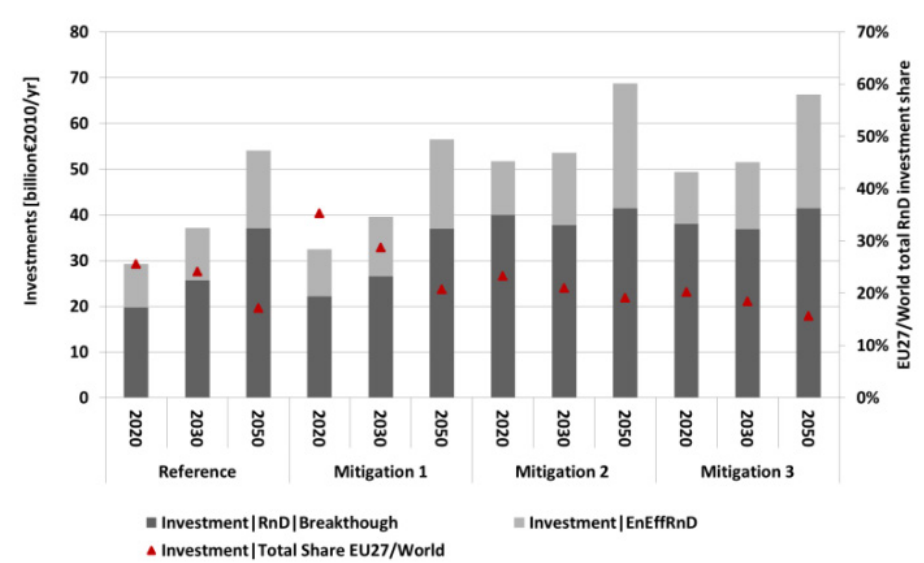

R\&D in WITCH: High Energy Efficiency

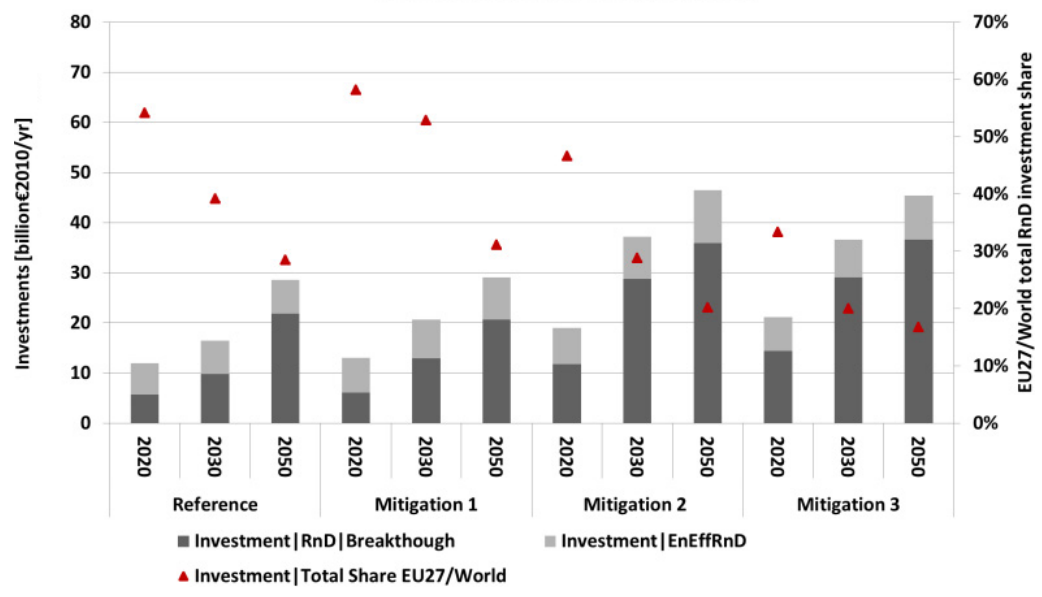

Figure 8. Investment in $R \& D$ in energy efficiency and breakthrough technologies in Europe. Results from the WITCH model, default (top panel) and high energy efficiency (bottom panel) technology cases.

breakthrough technology which is meant to replace oil, especially in the transport sector. This technology can be interpreted to represent advanced biofuels, hydrogen, or batteries for electric cars. ${ }^{13}$ Because of international spill overs of knowledge (see De Cian et al., 2012) for more details on the modeling of spillovers), investments in Europe would be higher under the global regime, the Mitigation 2 case, when also other regions invest in R\&D. Carbon trade, as foreseen in Mitigation 3, slightly reduces the investments compared to the Mitigation 2, but they still remain higher than in the unilateral climate policy case, Mitigation 1. Improvements in end-use efficiency

\footnotetext{
${ }^{13}$ The model would provide also R\&D investment in an analogous electric breakthrough technology, which may be interpreted as nuclear fusion or advanced, waste-free nuclear fission, and which substitutes traditional nuclear fission plants in the nuclear phase-out scenarios (not considered in the scenarios analyzed in this paper).
} 
reduce the $R \& D$ expenditures significantly. Understandably, there is no similar need to invest in efficiency improvements, if higher efficiency is assumed a priori. The need to breakthrough technologies is also lowered as less primary resources is needed for providing the same energy services.

\section{Macroeconomic and Trade Effects}

This section analyzes the feedback of technology and energy transformations described in the previous sections on the economy. The analysis is based on those models that explicitly describe the link between energy systems and the rest of the economy, namely EPPA, FARM-EU, MERGE-CPB, PACE, and WITCH.

The adoption of the $80 \%$ reduction target would induce changes in consumption, GDP, and investments already by 2020 . These changes would become more prominent over time and in 2050 effects are substantial. Figure 9 shows that the reduction in 2050 GDP ranges from slightly negative to $-10 \%$, with a median value of $-4.1 \%$ (Mitigation 1 versus reference, or $80 \%$ DEF versus $40 \%$ DEF). The reduction in consumption would be of a similar magnitude, though lower than GDP (median value $-3.23 \%$ ), which also accounts for the effects of other components, namely investments, government expenditures, and net exports. EU bears most of the economic burden as its median share of global GDP and consumption reductions is $96 \%$ (range 92-123\%) and $86 \%$ (range 66-125\%), respectively. These rather large reductions, however, are mainly experienced towards 2050, as reductions in both consumption and GDP are significantly lower in 2030 (GDP is 0.1 to $0.7 \%$ below reference, consumption 0 to $0.5 \%$ below).

Adjustments occur also on the production side of the economy. If the target becomes more stringent (Mitigation 1 versus reference policy case), value added generally declines, but the contraction is more severe in EI industries (up to $-40 \%$ as opposed to a maximum reduction of $-15 \%$ in NEI industries), see Fig. 9. ${ }^{14}$ EI industries are penalized relatively more by more expensive energy inputs. Although energy prices slightly decline (see Sec. 3 ), the $\mathrm{CO}_{2}$ price that the EU producing sectors would face acts as an additional tax on energy inputs. The magnitude of the effects differs by model and the individual ability to absorb input cost increases with the possibility of substituting alternative inputs (substitution elasticities and efficiency improvement).

The carbon price that the EU would need to enforce internally in order to achieve the EU-wide-80\% target changes the international market conditions, with the EU losing competitive advantage in EI goods, while gaining market share in NEI industries. What would happen if the rest of the world would enforce climate policies of similar stringency? By comparing the scenarios Mitigation 2 (80\% FRAG) and 1 (80\% DEF) we can understand to what extent, a more equally diffused climate policy across countries could restore global market conditions. With comparable mitigation efforts in

${ }^{14}$ For a more detailed analysis on the sectoral effects of the EU policy, see Förster et al. (2013). 

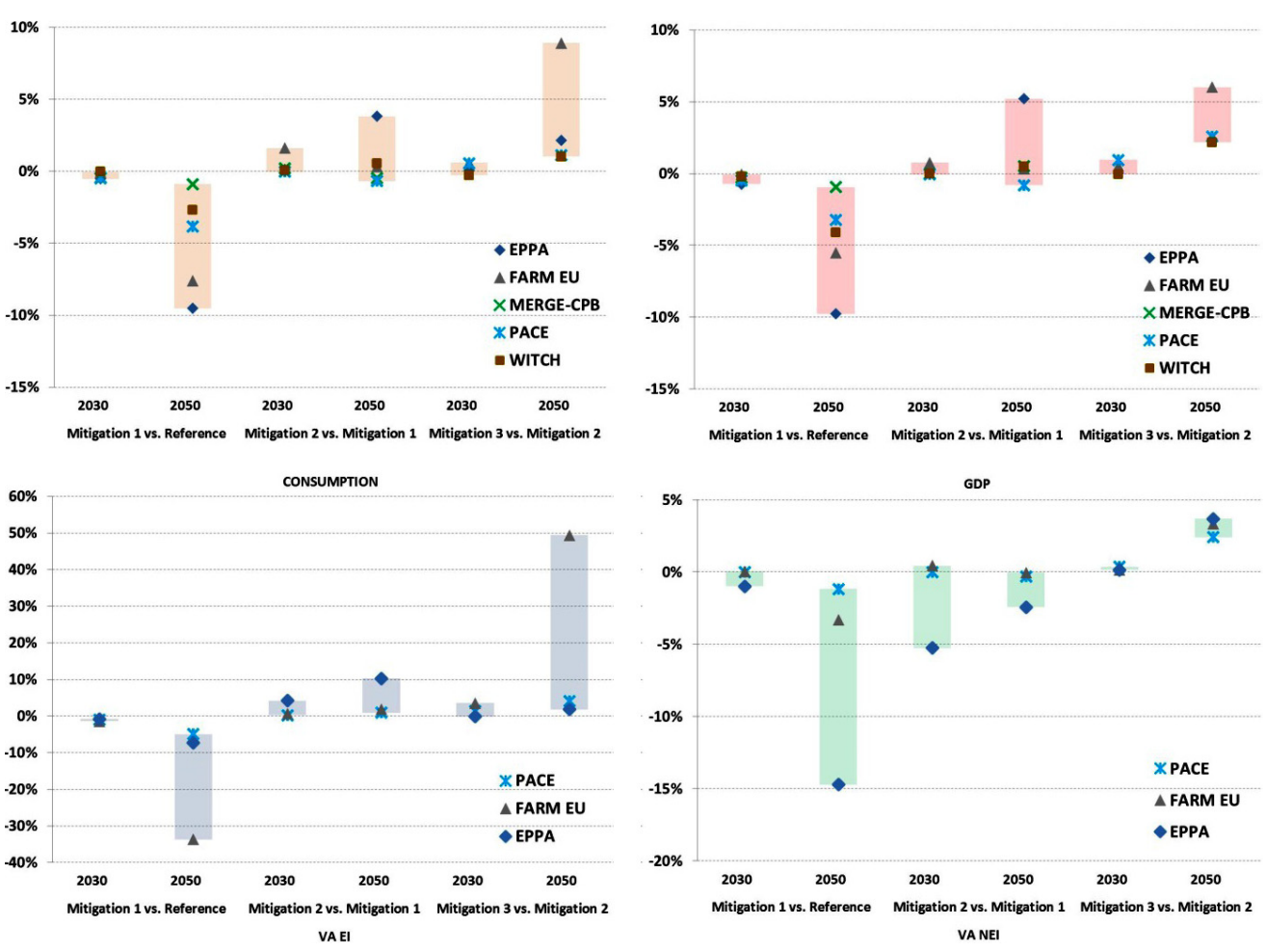

Figure 9. Consumption (upper left panel) and GDP (upper right panel) and value added percentage changes in energy-intensive (EI, lower left panel) and nonenergy-intensive (NEI, lower right panel) industries. Note the different scales.

other countries, production in Europe would be higher (Mitigation 2 versus Mitigation 1, or $80 \%$ FRAG versus $80 \%$ DEF) and total value added would go up, driven by the expansion in EI industries, see Fig. 9. These patterns are reflected in greater GDP and consumption in most models, as shown in Fig. 9. The range is actually quite broad. Consumption could increase up to $5 \%$ in 2050, although for a model the changes with respect to the Mitigation 1 case are close to zero (PACE). Yet, the increase would not be sufficient to offset the reduction compared to the reference policy case (40\% DEF). European net exports would respond accordingly, with EI industries gaining some more market share (in Mitigation 2) compared to the unilateral case, Mitigation 1. Yet, export of EI goods remains lower compared to the reference case.

Mitigation 2 scenario features a more even emission reduction target across world regions, but the abatement allocation remains inefficient because it assumes Europe cannot exchange carbon permits with the rest of the world, which is instead considered in the scenario Mitigation 3. Comparing Mitigation 3 and 2, we can trace the efficiency gains and the effect of carbon trade on energy and nonenergy goods. In a global $\mathrm{CO}_{2}$ market as in Mitigation 3, the EU would operate as a buyer of certificates, suggesting steeper marginal abatement costs compared to other regions. Thus, the EU would 


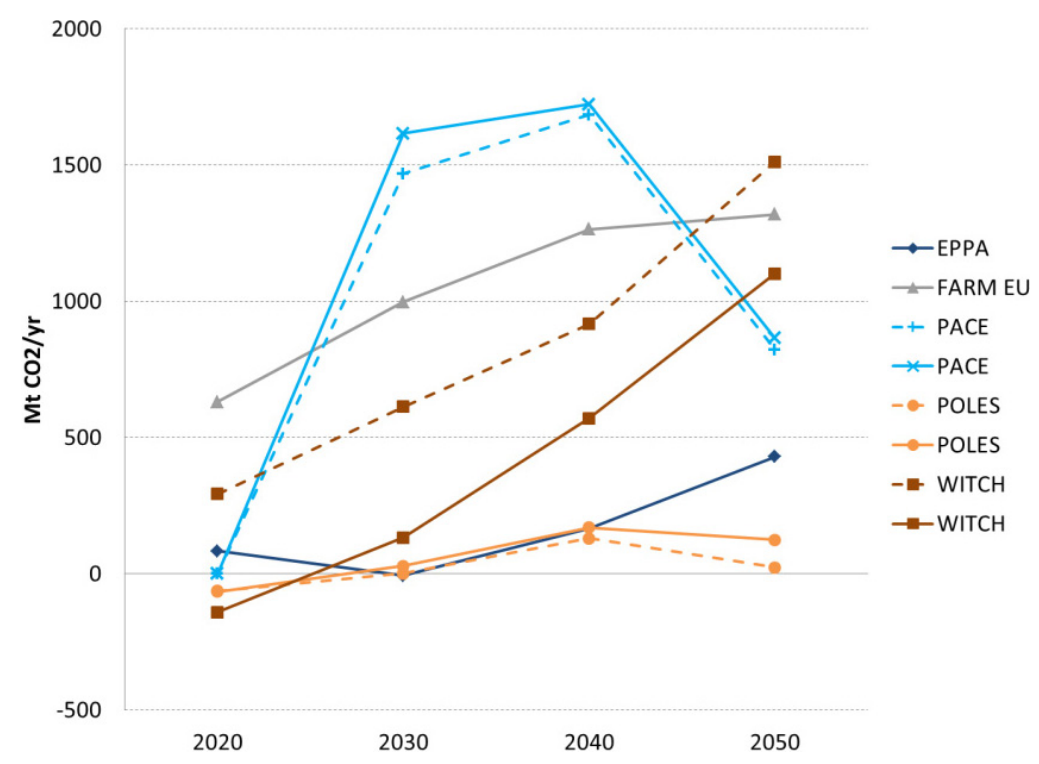

Figure 10. Emission permits purchased by the EU on the international market computed as difference in $\mathrm{CO}_{2}$ industrial emissions between Mitigation 3 (80\% GLOB) and Mitigation 2 (80\% FRAG), under default (solid lines) and high energy efficiency technology case (dashed lines).

benefit from efficiency gains under a global carbon trading scheme. Figure 10 shows that the difference of actual emissions reductions in Europe in Mitigation 3 compared to Mitigation 1 is positive, indicating the amount of emission rights purchased by the EU on the international market.

The possibility of purchasing emission permits from other countries would almost restore the global market conditions of the reference case. In some models, value added and net export of EI industries would increase above the reference levels already in 2030. The other macroeconomic aggregates would also go up. Consumption would increase up to $8 \%$ while GDP could reach a $6 \%$ increase compared to the Mitigation 2 case. Since $\mathrm{CO}_{2}$ trade would reallocate abatement in an efficient way, the marginal abatement costs of the EU would decline, except for the models that report similar emission prices for EU and rest of the world in Mitigation 2. The graphs in Fig. 11 plot the European $\mathrm{CO}_{2}$ price and the corresponding EU emissions for the scenarios Mitigation 2 (80\% FRAG) and Mitigation 3 (80\% GLOB). Note that the relation between the $\mathrm{EU} \mathrm{CO}_{2}$ price and $\mathrm{EU} \mathrm{CO} \mathrm{CO}_{2}$ emissions in Fig. 11 is not a classical marginal abatement cost curve because it is obtained by combining values from different model years.

The left panel shows that under global climate action without international emissions trading ( $80 \%$ FRAG), the $\mathrm{EU} \mathrm{CO}_{2}$ price will strongly increase if $\mathrm{EU} \mathrm{CO}_{2}$ emissions are restricted to about $1500 \mathrm{Mt}$ or below in PACE and WITCH. Obviously, reducing emissions below this critical point is technically ambitious, given today's set 

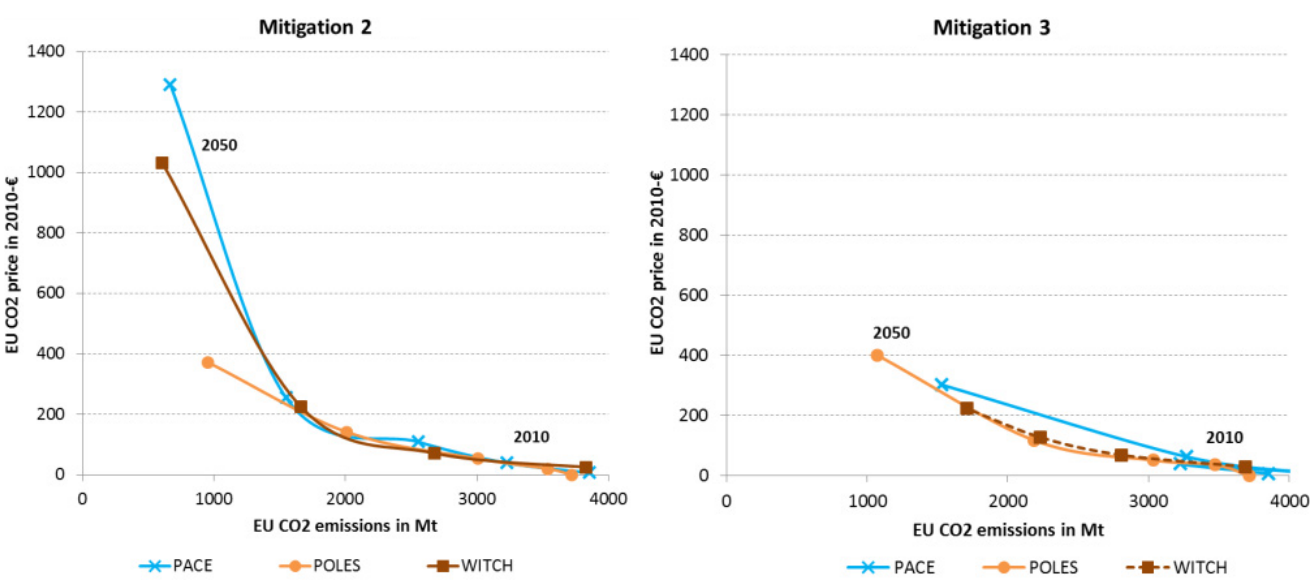

Figure 11. Relationship between the EU emission price and $\mathrm{CO}_{2}$ emissions in the Mitigation 2 (80\% FRAG) and Mitigation 3 (80\% GLOB) scenarios in the PACE, POLES, and WITCH models.

of technologies as represented in the models. The picture reflects an underlining convex and increasing marginal abatement costs. When allowing for international emissions trading (80\% GLOB), the strong, convex increase of marginal abatement costs observed over time in PACE and WITCH disappears. This happens because the EU imports emission permits from the rest of the world and can thus emit more. The $\mathrm{CO}_{2}$ price in POLES, on the contrary, stays below $400 €$ per ton in both scenarios and is hardly affected by international emissions trading (of which there is rather little, see Fig. 10). This reflects the similar emission prices, and the use of roughly similar mitigation options inside and outside the EU.

We also examine the results presented in this section under the assumption of a more optimistic view about energy efficiency improvements. Our results are qualitatively confirmed, though the magnitude of some effects, in particular those of negative effects, would be smaller. For instance, consumption and GDP losses in 2050 are between 1 and 2 percentage points lower. Net export in EI industries will still fall as a response to the unilateral $-80 \%$ reduction target, but to a much lesser extent, reaching $-5 \%$ in FARM-EU, as opposed to $-35 \%$ reported under the default technology case.

\section{Conclusions}

This paper examines how changes in the international climate regime would interact with the European climate policy strategy outlined in the Energy Roadmap and affect the European decarbonization strategy and costs. The paper analyzes realignments in energy and nonenergy trade patterns with the rest of the world, changes in the primary energy mix, changes in R\&D and renewable investment strategies, as well as the implications on consumption and GDP. 
The introduction of climate policies induces changes in energy trade patterns. Moving from a no-policy scenario to an existing-policies case (2020 targets plus 40\% GHG mitigation by 2050 for the EU and moderate policies for the rest of the world, $40 \%$ DEF) we observe, on average, a reduction in all energy imports. Coal imports are affected especially strongly in those models that exhibited high imports in the nopolicy scenario, whereas natural gas and oil imports are reduced to a lesser extent.

Introducing a more stringent climate policy target for the EU only and keeping climate ambitions at the reference level for the rest of the world, leads to slightly greater global emission reductions, even if emissions are still clearly too high in light of the $2^{\circ} \mathrm{C}$ target. In terms of energy markets, expenditures on energy imports are reduced under the more stringent EU policy, mostly because the volume of energy imports decreases while the price tends to stay close to the reference case level. Mitigation exerts pressure on the introduction of low carbon technologies and energy efficiency, lowering the demand for conventional fuels. This effect is mitigated by the penetration of CCS technology, which creates demand for fossil fuels. Consumers and producers in Europe bear most of the additional burden and inevitably face some economic losses. Changes in consumption, GDP, and investments would be induced starting early on, in 2020, and become more pronounced over time. By 2050, the median GDP contraction for the EU would be $-4.1 \%$ but it could reach $10 \%$ in CGE models. The reduction in consumption is qualitatively similar, though lower in magnitude as it excludes the effects of other GDP components, investment, government expenditures, and net exports. Economic output of EI industries is more negatively impacted, while nonenergy sectors gain some market share.

Global action, especially when paired with a well-operating global carbon market, could level the playing field, and reduce the burden for Europe significantly. Compared to the unilateral EU policy scenario (Mitigation 1, 80\% DEF), we observe an expansion of production and GDP in Europe in the Mitigation 2 (80\% FRAG), and Mitigation 3 (80\% GLOB) scenarios, driven by EI industries. The level of value added and net exports of EI industries would return very close to reference levels.

Climate and energy policy choices of other countries do not significantly affect the technology transition of Europe before 2050, whereas changes would occur as we get close to 2050. CCS technology plays a role in Mitigation 2, where a more binding target is fixed for non-EU countries. Allowing for a single global carbon market (Mitigation 3) makes an early introduction of CCS unnecessary. A common feature across models is the increasing role of biomass, nuclear, and nonbiomass renewable technologies for the EU in both Mitigation 1 and Mitigation 2 compared to the less important role in the reference and global carbon market scenarios (Mitigation 3), though the extent of the shares varies significantly. Moreover, the share of nonbiomass renewables and nuclear tends to be higher in models that do not foresee the option of combining fossil fuels or biomass with CCS.

Moving toward a case characterized by more global action (Mitigation 2), models agree on an increase in EU energy import volumes and a decrease in energy prices, but 
as these two components of import expenditure move in opposite directions, the aggregate impact can either lead to an increase or decrease in import expenditures, depending on which of the two factors dominates for a given model. When a global carbon market is also assumed (Mitigation 3), most models conclude that import volumes increase and prices decrease further. Differences across models reflect a range of assumptions concerning, for example, region-specific mitigation potentials, sensitivity to fuel prices, and the role of natural gas in the reference scenarios. These differences highlight the uncertainty concerning how energy trade may be affected by climate mitigation and technological developments and how these effects may depend on specific details of the mitigation regime, regional mitigation potentials, and technological parameters.

In the Mitigation 2 scenario, abatement allocation is still inefficient because it assumes that the EU cannot exchange carbon permits with the rest of the world, while in the global market of Mitigation 3 this becomes possible and shows that global trade may help reduce the cost of strong EU mitigation that occurs in the absence of such mechanism. In a global $\mathrm{CO}_{2}$ market, the EU could, additional to its own mitigation efforts, buy certificates, easing the domestic mitigation burden. The difference of actual emission reductions in Europe in Mitigation 3 compared to Mitigation 2 confirms the EU's role as a purchaser of emission rights.

Analysis of R\&D investments provided by the WITCH model indicates that, because of the international diffusion of knowledge and technology, R\&D investments in the EU would be higher under a global climate policy regime compared to Mitigation 1 or the reference case, as the impact would be leveraged by increased R\&D spending outside the EU. The analysis of global learning in solar-PV provided by MERGE-CPB suggests that global action could significantly reduce the costs of solar-PV in Europe, while the effect is much more moderate for wind power, a more mature technology. In contrast, European investments would not significantly lower technology costs in other countries.

Our results highlight the different dynamics of energy, technology and the economy in alternative future climate regimes. A unilateral move of the EU from a reference policy scenario based on existing climate policies toward a more stringent climate policy target (Mitigation 1) may be costly (median reduction for GDP and consumption $\sim 4 \%$, high end of the range 10\%) and the economic burden would be borne mostly by the EU. It would have only a minor impact on global emissions, wind, and solar technology costs, and clean energy innovation. This study did not assess possible co-benefits that might affect the overall assessment of costs and benefits (e.g., reduced health impacts from the combustion of fossil fuels) and, in general, a number of relevant processes fall outside the scope of the models (e.g., technology exports, ecosystem services, ecological impacts of mitigation).

The above described economic and climate related factors would change if more stringent mitigation action aiming to stay within the global $2^{\circ} \mathrm{C}$ target would be carried out in other countries and regions, as analyzed in scenarios Mitigation 2 and 3. The 
economic costs for the EU would be reduced, while at the same time technology innovation and energy system changes would be stimulated. Specifically, the high potential of international emissions trading analyzed in Mitigation 3 seems to be a valuable mechanism to overcome the critical point of emission reductions when the EU faces strong mitigation targets. A global carbon market can help to remove mitigation pressure from the system by equalizing abatement costs among different regions. The analysis concludes that global climate action for achieving the necessary emissions reductions is indispensable.

\section{References}

Anandarajah, G, S Pye, F Kesicki, W Usher and C McGlade (2011). TIAM-UCL global model documentation, UKERC, London. Available at http://www.ukerc.ac.uk/support/tiki-index. php?page=ES_TIAM-UCL_Documentation_2010. Accessed on 11 October 2013.

Ang, B (2005). The LMDI approach to decomposition analysis: A practical guide. Energy Policy, 33(7), 867-871.

Barreto, L and G Klaassen (2004). Emissions trading and the role of learning-by-doing spillovers in the bottom-upenergy-systems ERIS model. International Journal of Energy Technology and Policy, 2, 70-95.

Barreto, L and S Kypreos (2002). Multi-regional technological learning in the energy-systems MARKAL model. International Journal of Global Energy Issues, 17, 189-213.

Boeters, S and J Bollen (2012). Fossil fuel supply, leakage and the effectiveness of border measures in climate policy. Energy Economics, 34 (Supplement 2), 181-189.

Blanford, GJ, RG Richels and TF Rutherford (2009). Feasible climate targets: The roles of economic growth, coalition development and expectations. Energy Economics, 31 (Supplement 2), 82-93.

Böhringer, C and A Lange (2003). Efficiency, compensation, and discrimination: What is at stake when implementing the EU emissions trading scheme? ZEW Discussion Paper No. 03-73, Mannheim, Germany.

Böhringer, C and A Löschel (2006). Promoting renewable energy in Europe: A hybrid computable general equilibrium approach. The Energy Journal (Special Issue No. 2), 123-138.

Böhringer, C, A Löschel, U Moslener and TF Rutherford (2009). EU climate policy up to 2020: An economic impact assessment. Energy Economics, 31(2), 295-305.

Böhringer, C, EJ Balistreri and T Rutherford (ed.) (2012). Special issue on the role of border carbon adjustment in unilateral climate policy: Results from EMF 29. Energy Economics, 34 (Supplement 2), 95-250.

Bollen, J (2013). EU energy roadmap: Learning and intermittency. Paper presented at the 2013 International Energy Workshop.

Bollen, J, A Gielen and H Timmer (1999). Clubs, ceilings and CDM: Macroeconomics of compliance with the Kyoto protocol. The Energy Journal, International Association for Energy Economics (Special Issue), 177-206.

Bollen, J, P Koutstaal and P Veenendaal (2011). CPB study trade and climate change, April 2011, EC, DG Trade, Brussels, Belgium. Available at http://trade.ec.europa.eu/doclib/docs/ 2011/may/tradoc_147906.pdf.

Bosetti, V, C Carraro, M Galeotti, E Massetti and T Tavoni (2006). WITCH: A World Induced Technical Change Hybrid Model. The Energy Journal, Special Issue. Hybrid modelling of energy-environment policies: Reconciling bottom-up and top-down, pp. 13-38. 
Bosetti, V and E De Cian (2013). A good opening: The key to make the most of unilateral climate action. Environmental and Resource Economics, doi: 10.1007/s10640-013-9643-1.

Burniaux, J and J Oliveira-Martins (2000). Carbon emission leakages: A general equilibrium view, OECD Economics Department Working Paper 242, OECD Economics Department.

Carraro, C, E De Cian, L Nicita, E Massetti and E Verdolini (2010). Environmental policy and technical change: A survey. International Review of Environmental and Resource Economics, 4, 1-57.

Clarke, L, J Edmonds, V Krey, R Richels, S Rose and M Tavoni (2009). International climate policy architectures: Overview of the EMF 22 international scenarios. Energy Economics, 31(Suppl 2), 64-81.

Criqui, P and S Mima (2012). European climate - energy security nexus: A model based scenario analysis. Energy Policy, 41, 827-842.

Dechezleprêtre, A, M Glachant and Y Ménière (2008). The clean development mechanism and the international diffusion of technologies: An empirical study. Energy Policy, 36, 1273 1283.

De Cian, E, V Bosetti and M Tavoni (2012). Technology innovation and diffusion in less than ideal climate policies. An assessment with the WITCH model. Climatic Change (Special Issue: On the economics of decarbonization in an imperfect world), 114(1), 121-143.

European Commission (2011). Roadmap for moving to a competitive low carbon economy in $2050 \operatorname{COM}(2011) 112$ final, paper available at http://eur-lex.europa.eu/LexUriServ/LexUriServ.do?uri=COM:2011:0112:FIN:EN:PDF; overview available at http://ec.europa.eu/ clima/policies/roadmap/index_en.htm. Accessed on June 2013.

Förster, H, K Schumacher, E De Cian, M Hübler, I Keppo, S Mima and ED Sands (2013). European energy efficiency and decarbonization strategies beyond 2030 - a sectoral multimodel decomposition (forthcoming).

Hübler, M and A Löschel (2013). The EU decarbonisation roadmap 2050: What way to walk? Energy Policy, 55, 190-207.

Keller, W (2010). International trade, foreign direct investment, and technology spillovers. In Handbook of the Economics of Innovation, Vol. 2, B Hall and N Rosenberg (eds.). UK: Elsevier Publishers.

Keppo, I and S Rao (2007). International climate regimes: Effects of delayed participation. Technological Forecasting and Social Change, 74, 962-979.

Klepper, G and S Peterson (2006). Emissions trading, CDM, JI, and more: The climate strategy of the EU. The Energy Journal, 27(2), 1-26.

Knopf, B, Y-HH Chen, E De Cian, H Förster, A Kanudia, I Karkatsouli, I Keppo, T Koljonen, K Schumacher and DP van Vuuren (2013). Beyond 2020 - Strategies and costs for transforming the European energy system. Climate Change Economics, 4(Supplement 1), 1340001.

Koljonen, T and A Lehtilä (2012). The impact of residential, commercial, and transport energy demand uncertainties in Asia on climate change mitigation. Energy Economics, 34(Supplement 3), 410-420.

Luderer, G, C Bertram, K Calvin, E De Cian and E Kriegler. (2013). Implications of weak nearterm climate policies on long-term mitigation pathways. Climatic Change (Special Issue, October), doi:10.1007/s10584-013-0899-9.

Paltsev, S, J Reilly, H Jacoby, R Eckaus, J McFarland, M Sarofim, M Asadoorian and M Babiker (2005). The MIT emissions prediction and policy analysis (EPPA) model: Version 4, MIT Joint Program Report 125. Available at http://globalchange.mit.edu/files/document/ MITJPSPGC_Rpt125.pdf. Accessed on 11 October 2013. 
Paltsev, S, H Jacoby, J Reilly, Q Ejaz, F O’Sullivan, J Morris, S Rausch, N Winchester and O Kragha (2011). The future of U.S. natural gas production, use, and trade. Energy Policy, 39(9), 5309-5321.

Sands, RD, H Förster, CA Jones and K Schumacher (2013). Bio-electricity and land use in the Future Agricultural Resources Model (FARM). Climatic Change (EMF27 Special Issue), doi: 10.1007/s10584-013-0943-9.

Van Vuuren, DP, MGJ den Elzen, PL Lucas, B Eickhout, B Strengers, B van Ruijven, S Wonink and R van Houdt (2007). Stabilizing greenhouse gas concentrations at low levels: An assessment of reduction strategies and costs. Climatic Change, 81(2), 119-159. 